\title{
Формирование омических контактов к слою алмазоподобного углерода, осажденному на диэлектрическую алмазную подложку
}

\author{
() А.И. Охапкин, П.А. Юнин, Е.А. Архипова, С.А. Краев, С.А. Королев, М.Н. Дроздов, В.И. Шашкин \\ Институт физики микроструктур Российской академии наук, \\ 603087 д. Асронино, Кстовский район, Нижегородская обл., Россия \\ E-mail: andy-ohapkin@yandex.ru
}

Поступила в редакцию 15 апреля 2020 г.

В окончательной редакции 21 апреля 2020 г.

Принята к публикации 21 апреля 2020 г.

Описан процесс изготовления омических контактов к слою алмазоподобного углерода (DLC) при осаждении на него последовательно металлических слоев $\mathrm{Au} / \mathrm{Mo} / \mathrm{Ti}$. Контакты имели хорошие механические и адгезионные свойства. Их удельное контактное сопротивление варьировалось от $1.4 \cdot 10^{-4}$ до $6.4 \cdot 10^{-5} \mathrm{OM} \cdot \mathrm{cm}^{2}$ в зависимости от толщины слоя DLC. Изучена температурная зависимость слоевого сопротивления пленок. Показано, что тонкие слои DLC обеспечивают лучшие характеристики омического контакта из-за их более равномерной графитизации в процессе термического отжига.

Ключевые слова: алмазоподобный углерод, омические контакты, плазмохимическое осаждение, монокристаллический алмаз, термический отжиг.

DOI: 10.21883/FTP.2020.09.49822.14

\section{1. Введение}

Монокристаллический алмаз обладает высокой теплопроводностью, твердостью, химической инертностью. На сегодняшний день он рассматривается как один из перспективных материалов для будущих полупроводниковых приборов [1]. В то же время для полупроводникового алмаза не решены многие важные технологические задачи. В частности, большая энергия активации примесей алмаза затрудняет построение приборов с протеканием тока, поскольку усложняется получение омических контактов с низким удельным контактным сопротивлением $\rho_{\text {cont }}$. В литературе описан метод формирования омических контактов к монокристаллу алмаза с применением карбидообразующих металлов [2,3]. В недавней работе [3] изготовлены невплавные омические контакты $\mathrm{Au} / \mathrm{Mo} / \mathrm{Ti}$ к эпитаксиальным пленкам алмаза $p$-типа с $\rho_{\text {cont }}=4 \cdot 10^{-7} \mathrm{OM} \cdot \mathrm{cm}^{2}$ и исследовано влияние отжига на их свойства. Оказалось, что слой молибдена при отжиге препятствует диффузии титана в золото и окислению контактной области Тi/C. В работе [4] показано, что добавка тонкого подслоя DLC (Diamond Like Carbon) толщиной 1-3 нм улучшает свойства омических контактов $\mathrm{Pt} / \mathrm{Au}$ при изготовлении алмазных радиационных детекторов. Благодаря эффекту квантового туннелирования электроны из металлов легко проходят через тонкий слой DLC к алмазу.

В данной работе представлены результаты первого этапа разработки омических контактов к алмазу с использованием подслоя DLC и металлов $\mathrm{Au} / \mathrm{Mo} / \mathrm{Ti}$. Использование подслоя DLC заметно улучшает адгезию комбинированных контактов к алмазу, что облегчает выполнение фотолитографических операций. В отличие от известных методов формирования графитовых контактов к алмазу под действием лазерного или ионного облучения $[5,6]$ использование DLC позволяет формировать тонкие и гладкие контактные слои с заданной толщиной и оптимальным соотношением содержания $s p^{2} / s p^{3}-$ гибридных состояний атомов углерода.

\section{2. Методика эксперимента}

Тонкие пленки DLC на монокристаллической нелегированной диэлектрической НРНТ (High-pressure Hightemperature) подложке алмаза с ориентацией (001) получали методом плазмохимического осаждения в установке Oxford Plasmalab 80. Исходные реагенты - газообразный метан и добавка аргона для ионного ассистирования [7]. Пленки DLC переводили в проводящее состояние путем частичной графитизации в процессе быстрого термического отжига в среде аргона при температуре $900^{\circ} \mathrm{C}$ в течение 2 мин на установке AcuThermo AW 410 System. На следующем этапе формирования контактов проводили осаждение металлов методом электроннолучевого напыления в вакууме. Вольт-амперные характеристики (BAX) измеряли с помощью системы Keithley 4200-SCS. Температуру и время отжига выбирали, исходя из предварительных исследований методом вторично-ионной масс-спектрометрии (ВИМС) пленок DLC на кремнии (времяпролетный масс-спектрометр TOF. SIMS 5). Выше $700^{\circ} \mathrm{C}$ происходит существенное изменение в составе пленок: увеличивается доля $s p^{2}$-гибридных связей углерода, что указывает на начало графитизации. При дальнейшем нагреве до $900^{\circ} \mathrm{C}$ процесс усиливается и сопровождается потемнением пленок, а также снижением их слоевого сопротивления $R_{\mathrm{sh}}$ до единиц кОм/квадрат. 


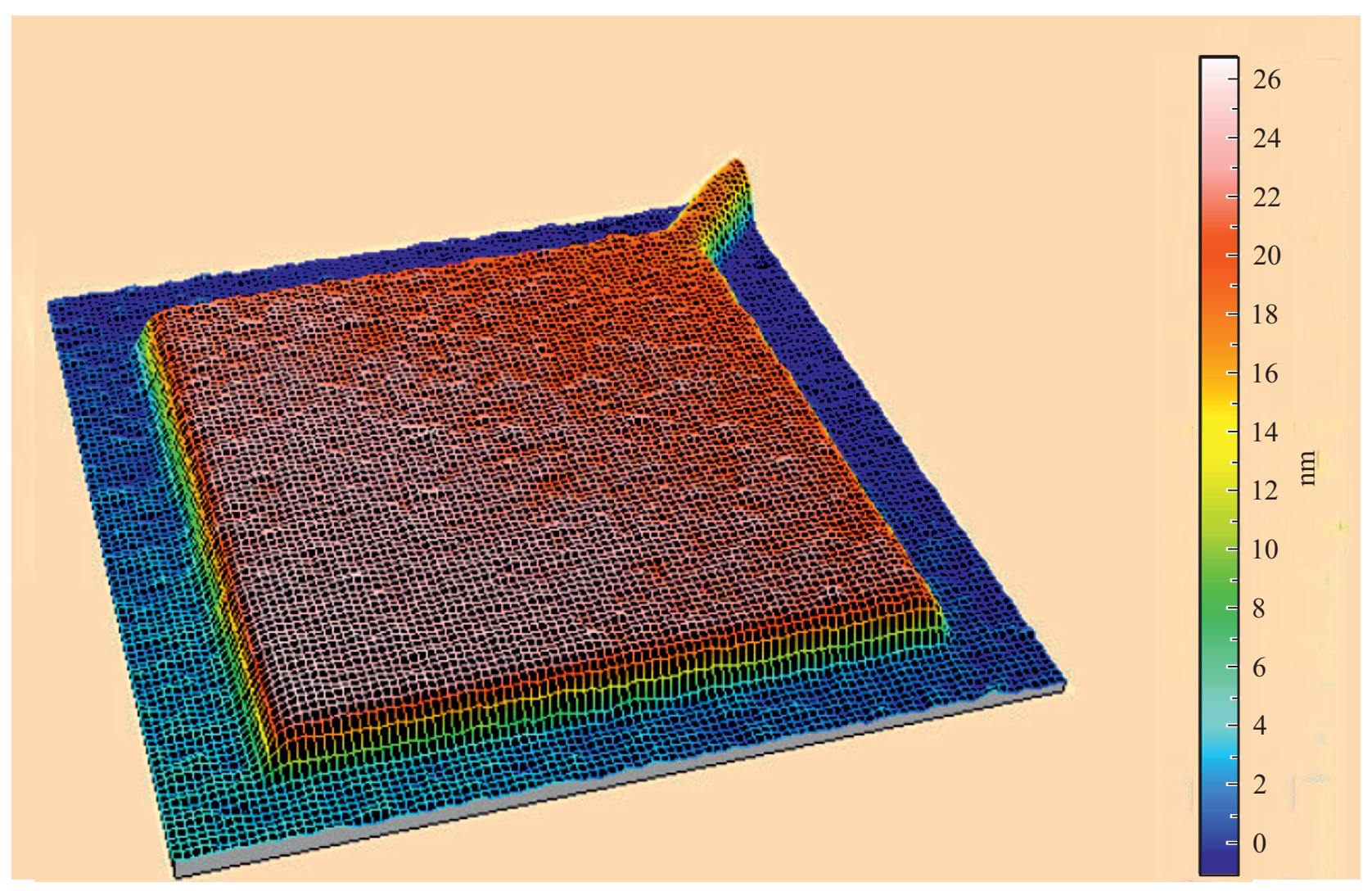

Рис. 1. Изображение пленки DLC (27 нм) на монокристалле алмаза после отжига при $900^{\circ} \mathrm{C}$, полученное в интерферометре белого света.

\section{3. Результаты и обсуждение}

В рамках данной работы исследовались структуры с толщиной слоев DLC 27 и 72 нм на поверхности монокристаллического алмаза. Было обнаружено, что изготовленные слои гладкие (шероховатость после отжига $\sim 1$ нм) и однородные (рис. 1). При этом они сохраняли хорошую адгезию к подложке. После напыления контактной металлизации была измерена практически линейная BAX в диапазоне напряжений от -10 до $10 \mathrm{~B}$ (рис. 2). Измерение удельного контактного сопротивления методом TLM (Transmission Line Method) для слоя DLC толщиной 27 нм (рис. 3) дало значение $\rho_{\text {cont }} \sim 6.4 \cdot 10^{-5} \mathrm{OM} \cdot \mathrm{cm}^{2}$, при этом $R_{\mathrm{sh}} \sim 10$ кОм/квадрат. Аналогичные измерения для пленки DLC толщиной 72 нм дали результат на 2 порядка хуже: $\rho_{\text {cont }} \sim 4.7 \cdot 10^{-3}$ Ом $\cdot$ см $^{2}$ при $R_{\text {sh }} \sim 4.5$ кОм/квадрат. Такое различие можно объяснить большей неоднородностью процесса графитизации толстой пленки DLC при тех же параметрах температуры и времени отжига. Об этом также свидетельствует то, что при последующем дополнительном отжиге толстой пленки DLC при температуре $450^{\circ} \mathrm{C}$ в течение 5 мин $\rho_{\text {cont }}$ улучшилось на порядок и составило $(1.4-1.8) \cdot 10^{-4} \mathrm{OM} \cdot \mathrm{cm}^{2}$; также произошло снижение $R_{\mathrm{sh}}$ пленки до 2.9 кОм/квадрат. Указанный диапазон $\rho_{\text {cont }}$ связан с неоднородностью

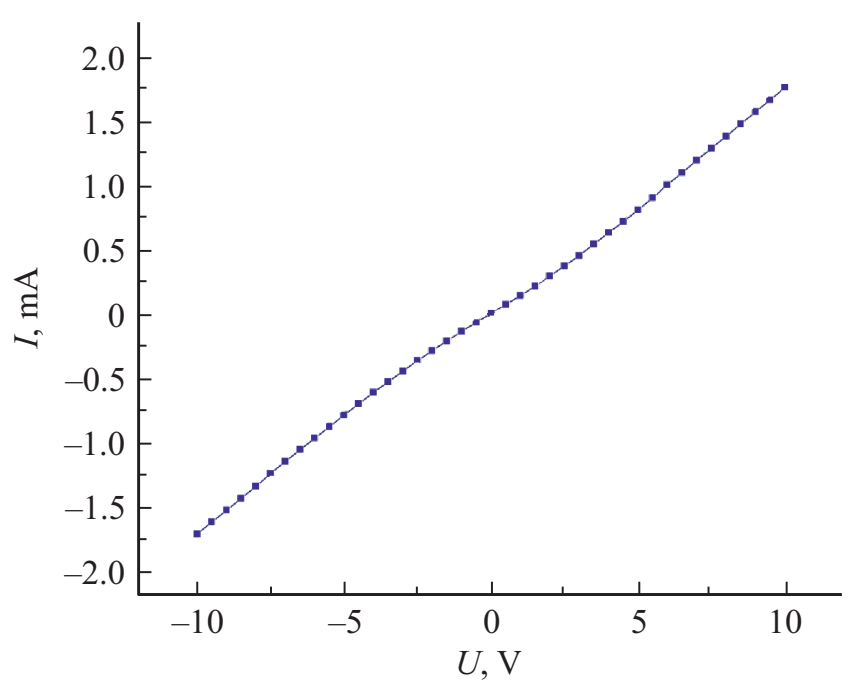

Pис. 2. BAX контакта $\mathrm{Au} / \mathrm{Mo} / \mathrm{Ti}$ к слою DLC в геометрии TLM, измеренная при комнатной температуре.

структуры. При этом ошибка измерения, полученная методом TLM, составляет не более $20 \%$.

Изучена зависимость слоевого сопротивления слоев DLC от температуры. При повышении температуры $R_{\mathrm{sh}}$ снижалось и при $280^{\circ} \mathrm{C}$ стало равным 1.7 кОм/квадрат 


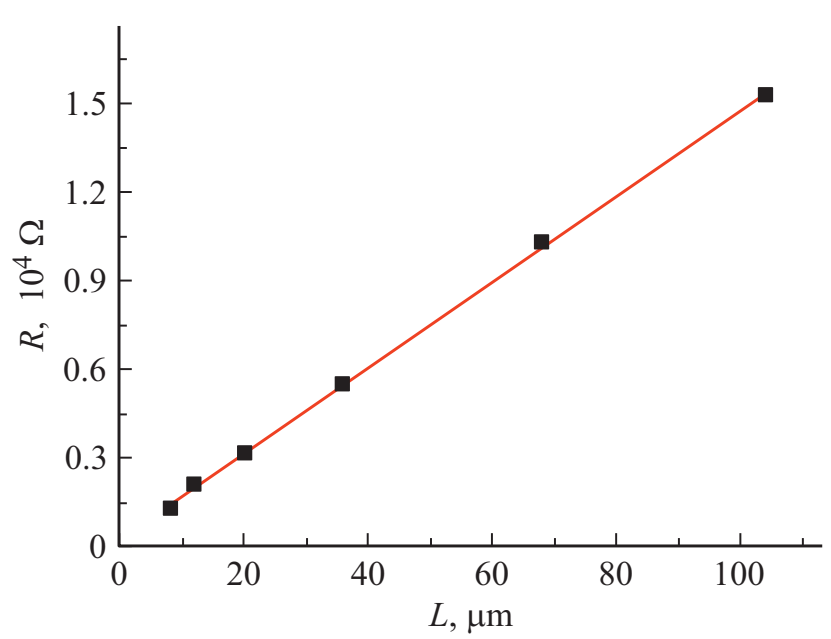

Pис. 3. Данные TLM для контакта $\mathrm{Au} / \mathrm{Mo} / \mathrm{Ti}$ к слою DLC, измеренные при комнатной температуре.

(для тонкой пленки), что в 5 раз ниже комнатного значения. Уменьшение $R_{\mathrm{sh}}$ с увеличением температуры (на примере легированных фосфором эпитаксиальных алмазных пленок) в литературе связывают с активацией прыжкового типа проводимости [8]. Вполне вероятно, что для слоев DLC также характерна прыжковая проводимость, обусловленная наличием близкорасположенных кластеров графита.

\section{4. Заключение}

В результате проведенных исследований была показана возможность формирования последовательности гладких слоев $\mathrm{Au} / \mathrm{Mo} / \mathrm{Ti} / \mathrm{DLC}$ с хорошими механическими свойствами и необходимой адгезией к монокристаллической диэлектрической алмазной подложке. При определенных режимах быстрого термического отжига указанных структур были получены омические контакты к слоям DLC, обладающие достаточно высокой токонесущей способностью, благодаря прыжковой проводимости. Представленный метод формирования контактов является простым, что открывает возможность перейти к следующему этапу исследований - изучению формирования омического контакта с подслоем DLC к эпитаксиальным слоям алмаза $n$ - и $p$-типа проводимости, выращенным на подложках с различной кристаллической ориентацией.

\section{Финансирование работы}

В работе использовалось оборудование ЦКП „Физика и технология микро- и наноструктур“. Осаждение и исследование слоев DLC выполнено при поддержке гранта Президента РФ для молодых кандидатов наук МК-3450.2019.2.

В части развития методики ВИМС работа поддерживалась проектом РФФИ № 18-02-00565.

\section{Конфликт интересов}

Авторы заявляют, что у них нет конфликта интересов.

\section{Список литературы}

[1] N. Donato, N. Rouger, J. Pernot, G. Longobardi, F. Udrea. J. Phys. D: Appl. Phys., 53, 093001 (2020).

[2] T. Tachibana, B.E. Williams, J.T. Glass. Phys. Rev. B, 45 20), 11975 (1992).

[3] М.Н. Дроздов, Е.В. Демидов, Ю.Н. Дроздов, С.А. Краев, В.И. Шашкин, Е.А. Архипова, М.А. Лобаев, А.Л. Вихарев, А.М. Горбачев, Д.Б. Радищев, В.А. Исаев, С.А. Богданов. ЖТФ, 89 (12), 1923 (2019).

[4] A. Galbiati, S. Lynn, K. Oliver, F. Schirru, T. Nowak, B. Marczewska, J.A. Duenas, R. Berjillos, I. Martel, L. Lavergne. IEEE Trans. Nucl. Sci., 56 (4), 1863 (2009).

[5] M. De Feudis A.P. Caricato, G. Chiodini, M. Martino, E. Alemanno, G. Maruccio, A.G. Monteduro, P.M. Ossi, R. Perrino, S. Spagnolo. Diamond Relat. Mater., 65, 137 (2016).

[6] S. Rubanov, A. Suvorova, V.P. Popov, A.A. Kalinin, Yu.N. Pal'yanov. Diamond Relat. Mater., 63, 143 (2016).

[7] А.И. Охапкин, П.А. Юнин, М.Н. Дроздов, С.А. Королев, С.А. Краев, Е.А. Архипова, Е.В. Скороходов, П.А. Бушуйкин, В.И. Шашкин. ФТП, 53 (9), 1229 (2019).

[8] T. Matsumoto, H. Kato, T. Makino, M. Ogura, D. Takeuchi, H. Okushi, S. Yamasaki. Jpn. J. Appl. Phys., 53, 05 FP05 (2014).

Редактор Г.А. Оганесян

\section{Formation of ohmic contacts to diamond-like carbon layer deposited on dielectric diamond substrate}

\section{A.l. Okhapkin, P.A. Yunin, E.A. Arkhipova, S.A. Kraev, S.A. Korolyov, M.N. Drozdov, V.I. Shashkin}

Institute for Physics of Microstructures, Russian Academy of Sciences, 603087 Afonino, Kstovsky district, Nizhny Novgorod region, Russia

Abstract In this paper describes the process of manufacturing ohmic contacts to diamond-like carbon (DLC) layer by depositing of $\mathrm{Au} / \mathrm{Mo} / \mathrm{Ti}$ metal layers. Contacts had good mechanical and adhesive properties. Their contact resistivity ranged from $1.4 \cdot 10^{-4}$ to $6.4 \cdot 10^{-5} \Omega \cdot \mathrm{cm}^{2}$ depending on the DLC layer thickness. The temperature dependence of the films sheet resistance was studied. It is shown that thin DLC layers provide better ohmic contact characteristics due to their more uniform graphitization during thermal annealing. 